九州大学学術情報リポジトリ

Kyushu University Institutional Repository

\title{
Functional Morphology of the Feeding Apparatus of the Cattle Tick, Haemaphysalis Longicornis
}

Yanagawa, Hisashi

Zoological Laboratory, Faculty of Agriculture, Kyushu University

Shiraishi, Satoshi

Zoological Laboratory, Faculty of Agriculture, Kyushu University

Uchida, Teruaki

Zoological Laboratory, Faculty of Agriculture, Kyushu University

https://doi.org/10.5109/23864

出版情報: 九州大学大学院農学研究院紀要. 32 (1/2)，pp.19-29，1987-12. Kyushu University バージョン：

権利関係 : 


\title{
Functional Morphology of the Feeding Apparatus of the Cattle Tick, Haemaphysalis longicornis*
}

\author{
Hisashi Yanagawa, Satoshi Shiraishi and Teru Aki Uchida \\ Zoological Laboratory, Faculty of Agriculture, \\ Kyushu University 46-06, Fukuoka 812, Japan
}

(Received March 30, 1987)

\begin{abstract}
From the viewpoint of the functional morphology, this report presents scanning electron and light microscopic observations on the feeding apparatus of the adult cattle tick, Haemaphysalis longicornis. The digits of the chelicerae act as a cutting organ for host skin and tissues. Protrusion of the whole chelicerae may be effected by an increase in internal body pressure and regulated by the cheliceral retractor muscles. The cheliceral sheath and hypostome bear many denticles which stabilized attachment of ticks to a host. Pulsations of the hypostomal membrane appear to be associated with a flowing of host blood and tick saliva. The labrum seems to close the pharyngeal orifice so that an inflow of saliva into the pharynx is prevented. The function of the salivarium is thought to be a salivary valve, because its floor undergoes a vertical motion by antagonistic actions of the constrictor muscles of the ala. Thus, a mixture of host blood and tick saliva would be precluded by the regulation among the labrum, the salivarium and the constrictor muscles of the ala. The pharynx functions as a sucking pump for host blood by contraction and relaxation of its dilator and constrictor muscles.
\end{abstract}

\section{INTRODUCTION}

The feeding mechanism of ticks has been studied for a long time in relation to disease transmission and host immunity (Arthur, 1962, 1965; Balashov, 1972 ; Kemp et $a l ., 1982$ ), and the structure of the feeding apparatus has been well elucidated in several species of ixodids (e.g. Gregson, 1960 for Dermacentor andersoni ; Kemp and Tatchell, 1971 for Boophilus microplus; Balashov, 1972 for Hyalomma asiaticum) and argasids (e. g. Sonenshine and Gregson, 1970 for Ornithodoros kelleyi ; Guirgis, 1971 for Argas arboreus). To our knowledge, however, there has been no morphological study on the feeding apparatus of the genus Haemaphysalis, except for the anatomical studies on $H$. punctata (Nuttall et al., 1908) and H. flava (Saito, 1960). The physiology of feeding in the cattle tick, H. longicornis has been solved in some degree (Kitaoka, 1967, 1977), because of the economic importance of this species as a most dominant tick in pastures of Japan and as the vector for theileriosis. However, it is impossible to understand well the feeding mechanism of ticks without revealing the structure and functions of the feeding apparatus. Therefore, the aim of this study is to examine with the scanning electron and light microscopes the structure of the feeding apparatus of the adult $H$. longicornis, and to discuss its functional morphology.

* Reprint requests to the second author. 


\section{MATERIALS AND METHODS}

The ticks used in this study are of the non-parasitic stage of the adults (Haemaphysalis longicornis) which were collected by the flagging method on the pastures in the Fukuoka and Oita Prefectures.

For scanning electron microscopy, the ticks were preserved in $70 \%$ ethanol, fixed to the specimen stubs by silver paint, and dried overnight in desiccators. The specimens were examined in an Hitachi SSM-2A scanning electron microscope $(10 \mathrm{kV})$, following coating with gold.

On the other hand, for light microscopy, the ticks were incised on the cuticula by a lazor blade, and fixed with cold $1.5 \%$ glutaraldehyde in Millonig's buffer ( $\mathrm{pH} 7.4$ ). After being thoroughly rinsed with the same buffer, the ticks were post-fixed with $1 \%$ osmium tetroxide in the same buffer, dehydrated with acetone and embedded in epoxy resin. Sections $(\sim 1.5 \mu \mathrm{m})$ were cut on a Porter-Blum MT-1 microtome, and stained with toluidine blue.

\section{RESULTS AND DISCUSSION}

\section{Scanning electron microscopical observations on the external structure}

The capitulum of Haemaphysalis Iongicornis is composed of the following four parts ; i. e. a pair of palps and chelicerae, a hypostome and a basis capitulum (Fig. la, b). Each palp consists of four segments ; a number of setae are found on segments 13 and palpal organ on a small segment 4 (Fig. la, b). It has been known that these palpal receptors are involved in the exploration and selection of an attachment site as well as tarsal and cheliceral receptors (Waladde and Rice, 1982). The chelicerae consist of a pair of rigid cuticular shafts, and each shaft bears a cheliceral digit at its apex, which can cut the skin and tissues of the host (Fig. la, b). The chelicerae are enclosed within the cheliceral sheaths of sclerotized cuticular tubes which protrude from the anterior part of the basis capitulum (Fig. la, b). The small denticles on the dorsal surface of the cheliceral sheath (Fig. la) are lacking in argasids and some prostriate ticks (genus Lxodes), both of which do not secrete cement (Kemp et al., 1982) ;

Fig. 1. Scanning electron micrographs showing dorso-lateral (a) and ventro-lateral (b) views of the capitulum of a female Haemaphysalis longicornis. Note the chelicerae and the cheliceral digits protruding from the cheliceral sheath by the handling depression of the tick body. The following abbreviations are used in Figs. 1-5: A, ala ; B, basis capitulum ; $\mathrm{C}$, chelicera ; $\mathrm{Ca}$, constrictor muscles of the ala ; $\mathrm{Cd}$, cheliceral digit ; $\mathrm{Cf}$, camerostomal folds ; $\mathrm{Cn}$, central nerve mass ; Cs, cheliceral sheath ; Dc, dorsal constrictor muscles of the pharynx ; F, food channel ; Fe, flexor and extensor muscles of the cheliceral digit ; H, hypostome ; Hm, hypostomal membrane ; L, labrum; Lc, lateral constrictor muscles of the pharynx ; Ld, lateral dilator muscles of the pharynx ; Lm, levator muscles of the capitulum ; $\mathrm{M}$, oval membraneous window ; $\mathrm{P}$, palp ; Pa, porose area ; $\mathrm{Ph}$, pharynx ; Po, palpal organ ; P1, palpal segment 1 ; P2, palpal segment 2 ; P3, palpal segment 3 ; P4, palpal segment 4 ; R, cheliceral retractor muscles ; $\mathrm{S}$, salivarium ; Sc, scutum; Sd, salivary duct ; Sp, subcheliceral plate ; Va, ventral articulation between the capitulum and the idiosoma ; Vc, ventral constrictor muscles of the pharynx ; Vd, ventral dilator muscles of the pharynx. 

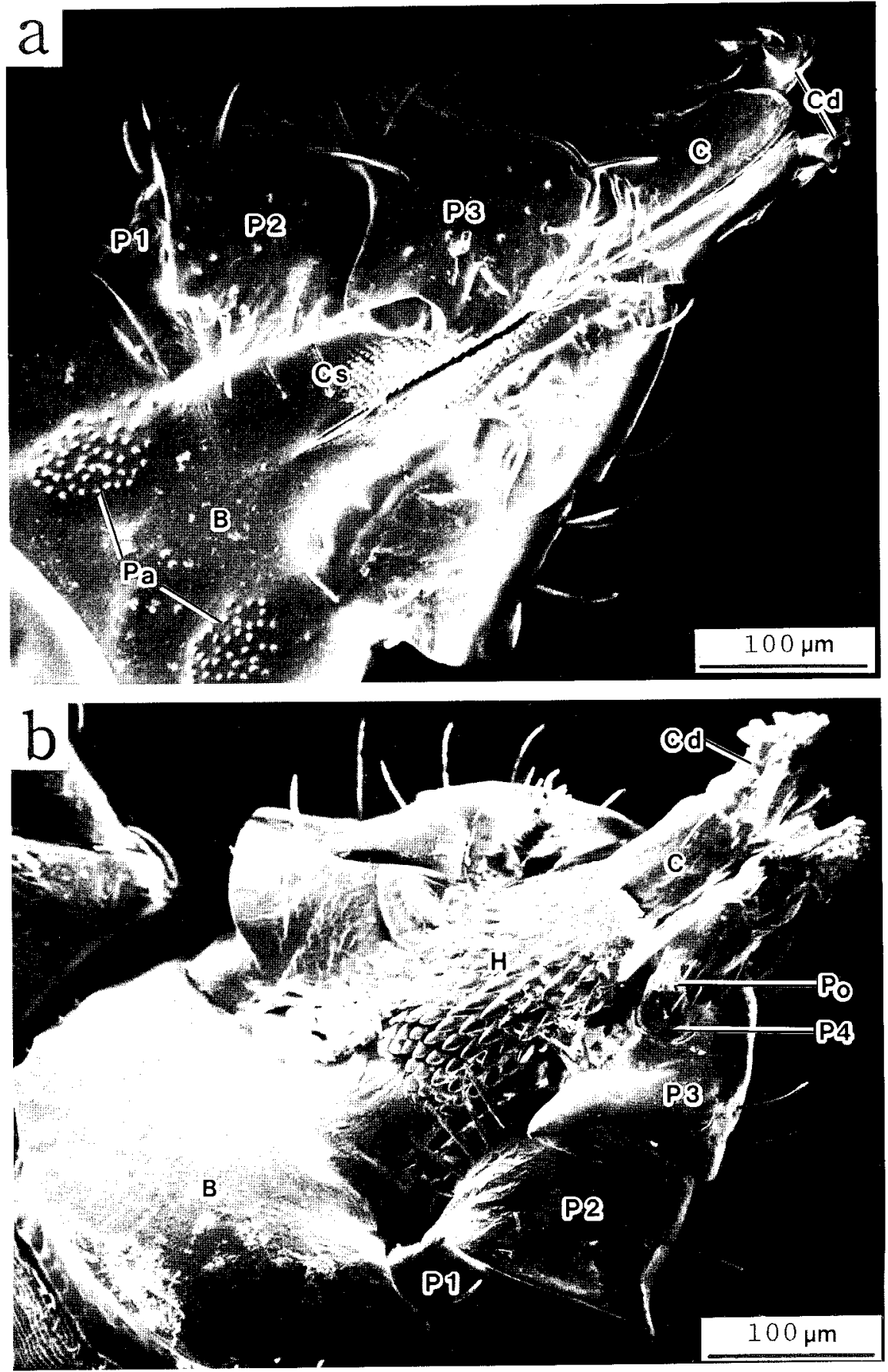
therefore, these denticles become embedded in attachment cement and may help to secure tick attachment. The ventral wall of the basis capitulum is prolonged anteriorly to form the hypostome whose external side has large recurved denticles by which attachment of ticks is still more strengthened (Fig. lb). The female has a pair of porose areas on the dorsal side of the basis capitulum (Fig. la), but the male is devoid of them.

\section{Light microscopical observations on the internal structure}

The cheliceral sheath, hypostome, basis capitulum and scutum are formed of sclerotized cuticle which stained blue or light blue with toluidine blue. On the other hand, camerostomal folds and a ventral articulation between the capitulum (gnathosoma) and the idiosoma are made up of non-sclerotized cuticle which took a purple in toluidine blue stain (Fig. 2). The presence of these non-sclerotized cuticles may allow the capitulum to move dorso-ventrad to some extent.

The chelicera is a sclerotized cuticular tube, becoming swollen proximally. The oval membraneous window situated dorsally and about two-thirds back from the tip, may permit the chelicera to bend. The cheliceral digit is provided with the flexor and extensor muscles which arise from the distended base of the cheliceral shaft (Figs. 2 and 3a). Host skin is penetrated by cutting action of the cheliceral digit which move

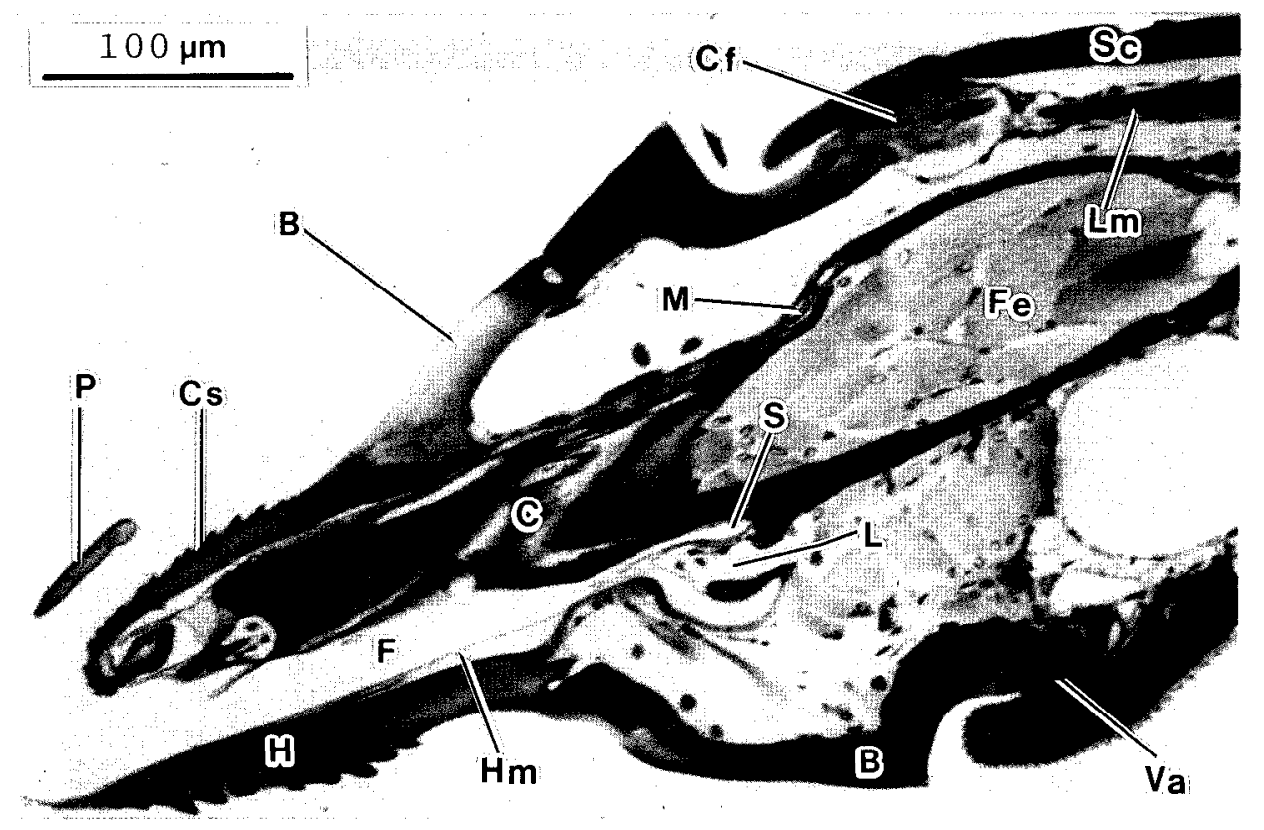

Fig. 2. Light micrograph showing para-sagittal section of the capitulum of a male $H$. longicomis. Sclerotized cuticle (cheliceral sheath, chelicera, hypostome, basis capitulum and scutum) and non-sclerotized cuticle (camerostomal folds and ventral articulation) stained blue and purple with toluidine blue, respectively. Abbreviations : see the legend to Fig. 1. 

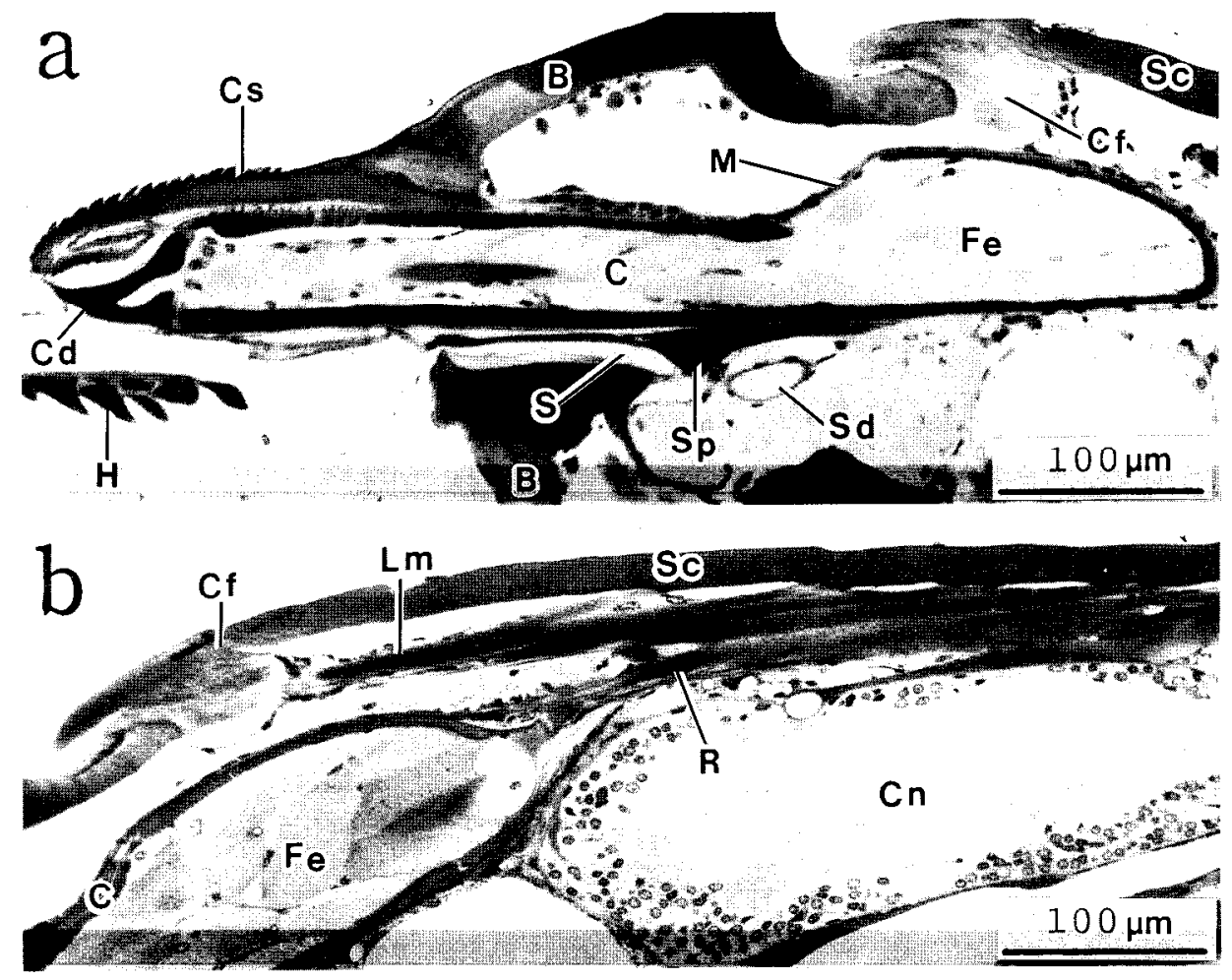

Fig. 3. Light micrographs showing para-sagittal sections of the chelicera in a male $H$. longicornis. Toluidine blue staining. a) The chelicera bears the cheliceral digit at its tip, which is provided with the flexor and extensor muscles. Oval membraneous window situates about two-thirds back from the apex. b) The cheliceral retractor muscles which seem to regulate protrusion of the chelicera insert on the base of the chelicera. Abbreviations : see the legend to Fig. 1.

by actions of these antagonistic muscles, and deeper insertion may be caused by a forward movement of the whole chelicera. Arthur (1946 for Ixodes ricinus, 1951 for Ixodes hexagonus, 1957 for Dermacentor parumapertus) has insisted that protrusion of the chelicerae is effected by contraction of the dorso-ventral somatic muscles, resulting pressure within the body cavity forcing the cheliceral shafts out through their sheaths. In $\mathbf{H}$. longicornis also, protrusion of the chelicerae caused by depressing the tick body became visible (Fig. la, b). The cheliceral retractor muscles seem to regulate the protrusion degree of the chelicera inserted on the base of each chelicera (Fig. 3b).

The food channel which extends from the buccal opening to the pharyngeal orifice, is a common duct for the intake of host blood and for the output of tick saliva. The floor of the food channel forms a V-shaped groove of the hypostome, the roof of the groove being covered by a thin hypostomal membrane (Figs. 2 and $4 \mathrm{a}$ ). This membrane of other ixodids has been thought to have the following functions in feeding: i. e. in Dermacentor andersoni, pulsations of membrane may assist a flowing of host blood and 

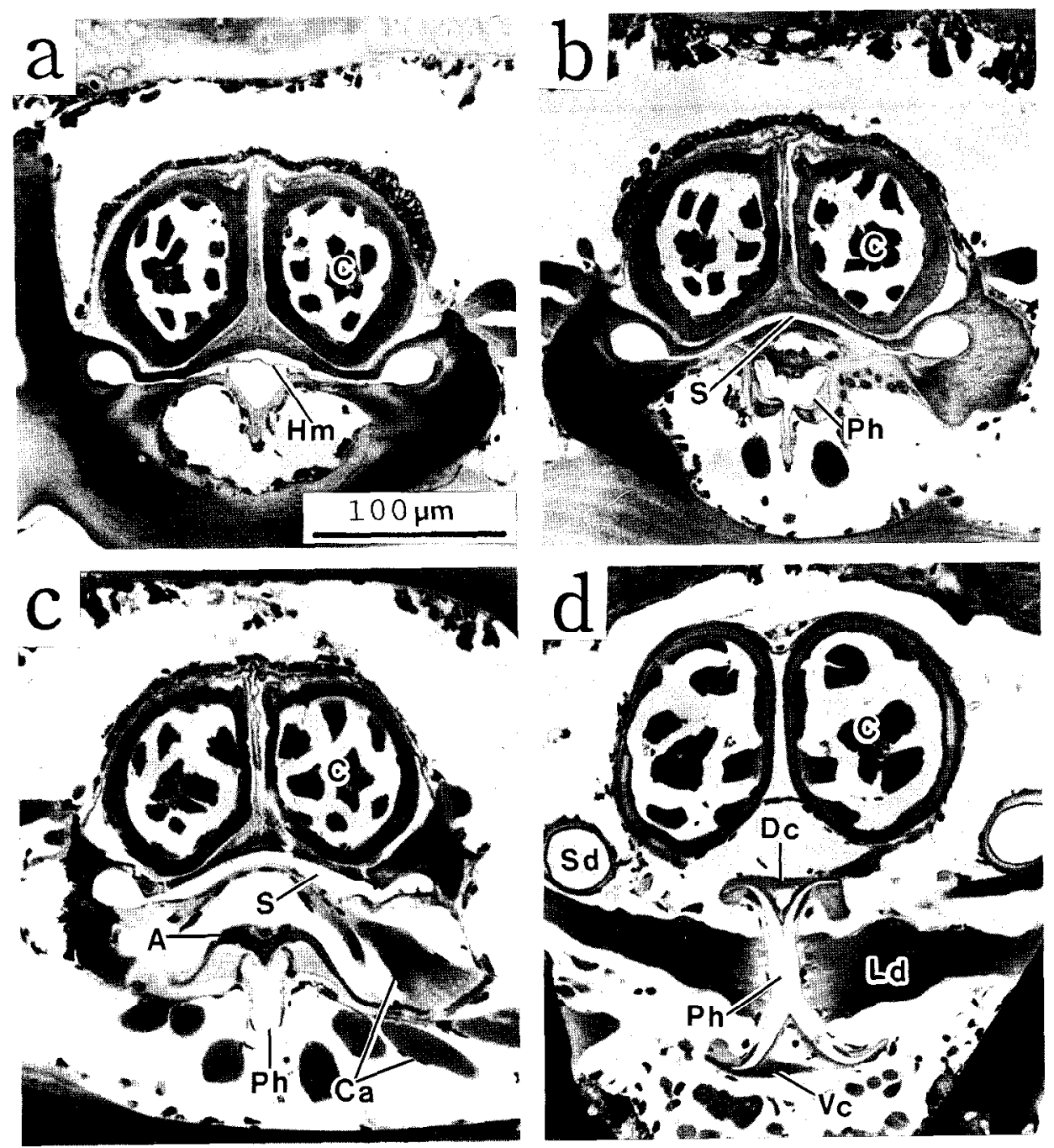

Fig. 4. Light micrographs showing cross sections of the capitulum of a female $H$. longicornis at successive levels from anterior to posterior (a-d). The cutting levels (ad) are shown in Fig. 6. Toluidine blue staining. The scale as in (a). Abbreviations : see the legend to Fig. 1.

tick saliva, and the rising and depressing action of the membrane also appears associated with regulation of salivation (Gregson, 1960) ; on the other hand, $m$ Boophilus microplus, in the resting position the hypostomal (gutter) membrane may be raised to block the food channel, and in the feeding position this membrane may be lowered to open the food channel at the same time as the pharyngeal valve opens (Kemp and Tatchell, 1971).

In H.longicornis, the labrum of a flexible tongue-like structure is shorter (Fig. 2) 
than that of argasids. Argasids possess the extensive labrum: in Argas persicus (Robinson and Davidson, 1913a) and in Ornithodoros papillipes (Sen, 1935), the function of the labrum seems to close the pharyngeal orifice so that saliva is forced into the feeding lesion ; moreover, in Ornithodoros kelleyi and Ornithodoros denmarki (Sonenshine and Gregson, 1970) and Argas arboreus (Guirgis, 1971), the labrum act as a prepharyngeal valve which is activated by hydrostatic pressure. On the contrary, because the labrum of ixodids is short, it is unlikely that it could exclude saliva from the food channel or act as a valve (Kemp et al., 1982).

The salivarium, which lies above the labrum, (Fig. 2) is roofed by the subcheliceral plate (Fig. 3a), into whose postero-lateral angles the two salivary ducts open. In terms of the function, the salivarium has been regarded as a salivary valve, a reservoir or a pump (Kemp et al., 1982) : in D. andersoni (Gregson, 1960) and A. arboreus (Guirgis, 1971), the salivarium cannot be considered a reservoir for saliva, because strong sclerotization of its wall incapacitates the salivarium from remarkable expansion ; however, the salivarium is described as a salivary reservoir in Hyalomma asiaticum (Balashov, 1972) and thought to function as a salivary valve or as a small reservoir in B. microplus (Kemp and Tatchell, 1971).

The pharynx whose wall is composed of an inner cuticular layer and an outer thin epithelial layer, shows a Y-shape in cross sections just behind the pharyngeal orifice (Fig. 4b). In subsequent sections, the ala or a wing-like cuticular extension is observed at the dorsal side of the pharynx ; in $H$. longicornis, the constrictor muscles pass dorsally from the ala to the floor of the salivarium and connect ventrally to the ala and the basis capitulum (Fig. 4c). The similar muscles are present in D. parumapertus (Arthur, 1957), D. andersoni (Gregson, 1960) and H. asiaticum (Balashov, 1972), but absent in B. microplus (Kemp and Tatchell, 1971) ; Arthur (1957) suggests that these muscles function antagonistically and are associated with closing and opening of the pharynx. At the middle and the posterior parts, cross sections of the pharynx show an X-shaped (or a double Y-shaped) appearance (Fig. 4d) which is seen also in other metastriate ticks, e. g. the genus Hyalomma (Balashov, 1972), Boophilus (Kemp and Tatchell, 1971), Rhipicephalus (Till, 1961) and Dermacentor (Arthur, 1957; Gregson, 1960) ; while in prostriate ticks, the genus Lxodes (Arthur, 1946, 1951) and argasid ticks, e.g. the genus Ornithodoros (Sen, 1935; Sonenshine and Gregson, 1970) and Argas (Robinson and Davidson, 1913b; Guirgis, 1971), the pharynx has a triple Y-shaped cross-section. At this level, the constrictor muscles attach to the dorsal, ventral and lateral walls of the pharynx, and the dilator muscles pass from the lateral and ventral walls of the pharynx to the basis capitulum (Figs. $4 \mathrm{~d}$ and $5 \mathrm{a}-\mathrm{c}$ ). The pharynx changes the capacity of the inner cavity by contraction or relaxation of these muscles (Fig. 5a, b), and functions as a sucking pump for host blood.

Based on the above results, the feeding apparatus of $H$. Zongicornis is reconstructed in Fig. 6, being morphologically similar to that of other metastriate ticks. As mentioned above, however, information on the function of the feeding apparatus varies with tick species and/or investigators, and consequently confusion arises in the mechanism of feeding and salivation.

In conclusion, the feeding mechanism of the cattle tick H. longicornis, seems to be as follows. Host blood flows through the food channel by pulsations of the hypostomal membrane, and reachs the oesophagus which links the pharynx and the midgut, by 
pumping up of the pharynx. Opening and closing of the pharynx (pharyngeal valve) are effected by the constrictor muscles of the ala. These constrictor muscles also cause the floor of the salivarium to move vertically by contraction or relaxation, thus the salivarium in $\mathbf{H}$. Iongicornis appears to act as a salivary valve, but unlikely to function as a reservoir for the bulk of saliva because its sclerotized wall precludes the ability of conspicuous expansion. The labrum in $H$. longicornis seems not to have such a

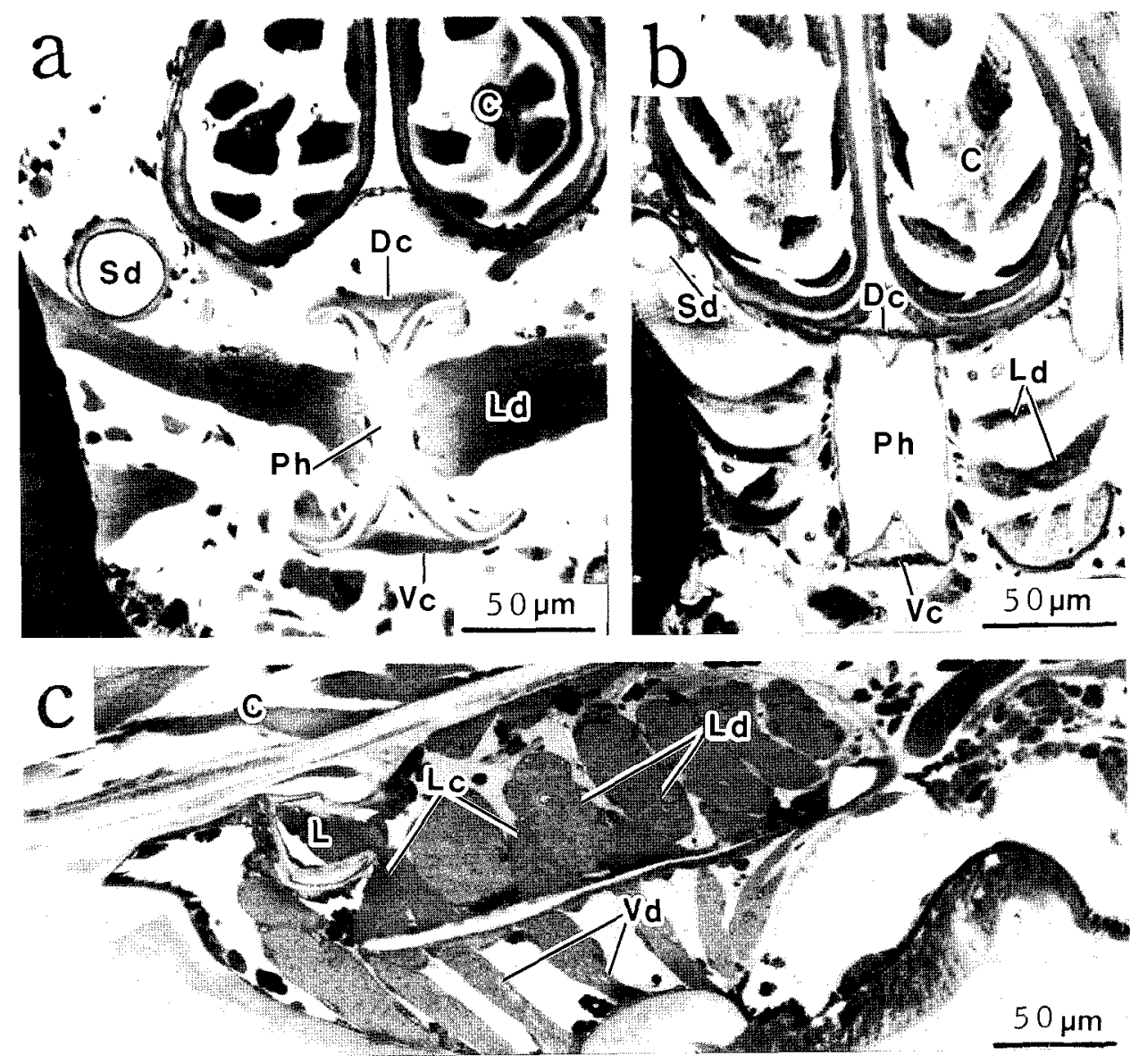

Fig. 5. Light micrographs of the muscle attachment to the pharynx. Toluidine blue staining. a) and b) Cross sections of a female $\mathbf{H}$. longicornis showing the situations of the pharynx when the lateral dilator muscles relaxed and contracted, respectively, and attachment of the dorsal and ventral constrictor muscles which seem to grasp expansion of the pharynx. c) Para-sagittal section of a male tick showing the running direction of the lateral and ventral dilator muscles, and the lateral constrictor muscles of the pharynx. Abbreviations: see the legend to Fig. 1.

Fig. 6. Diagramatic reconstruction in a para-sagittal section of the capitulum of $H$. longicomis. The symbols indicated on the vertical lines show the cutting levels in Fig. $4 \mathrm{a}-\mathrm{d}$. (opposite page) 


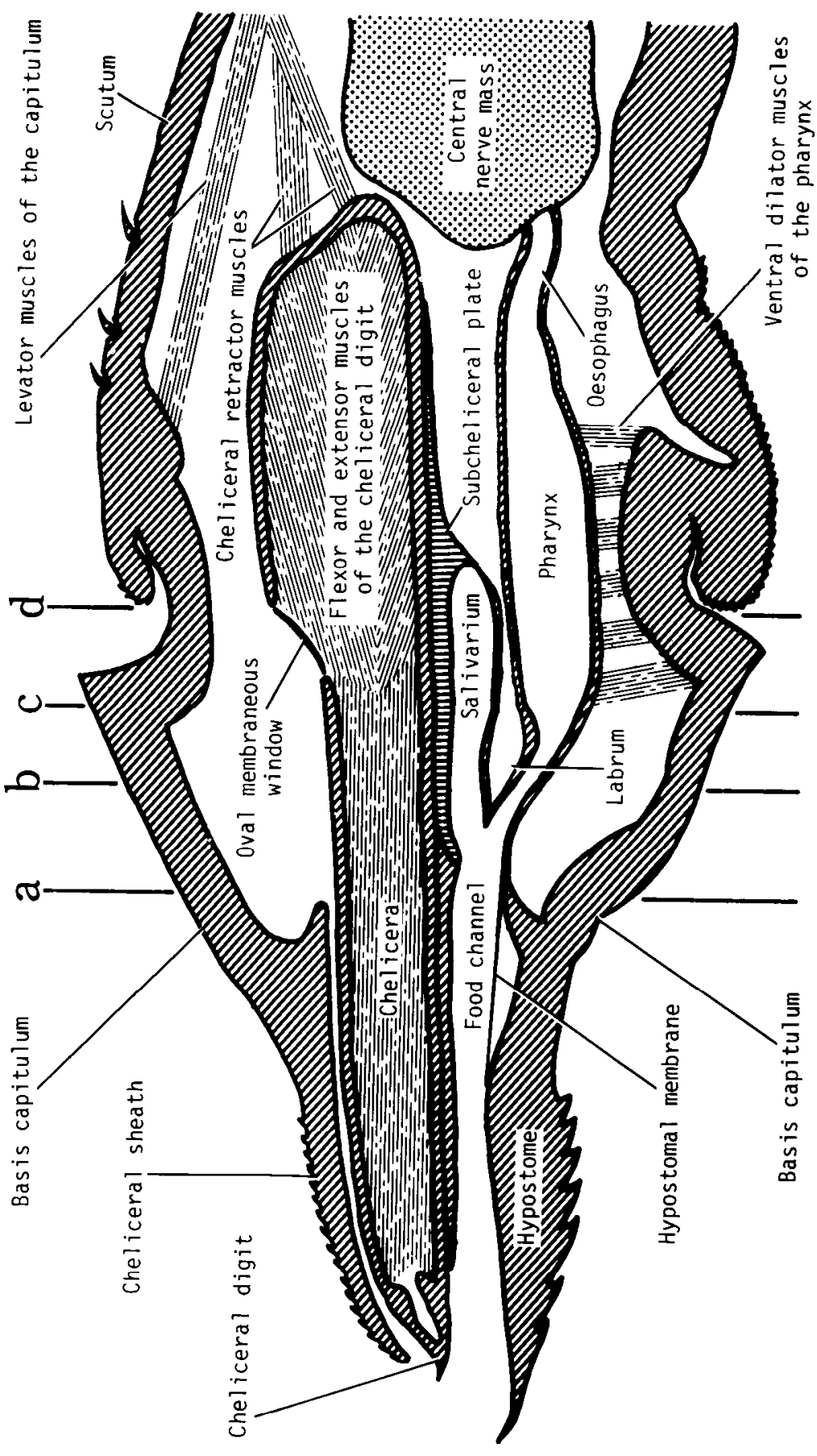


function of saliva exclusion as in argasids, but is long enough to close the pharyngeal orifice so saliva does not flow into the pharynx. Therefore, a mixture of host blood and tick saliva would be prevented by the complexly and delicately adjusted balance among the labrum, the salivarium and the ala whose constrictor muscles attach to the floor of the salivarium.

\section{ACKNOWLEDGEMENTS}

We are greatly indebted to the staffs of Kujū Agricultural Research Center of Kyushu University and Kyushu University Farm, for their kind help in collecting ticks ; Dr. T. Mōri of our laboratory, for his useful suggestions ; Mr. H. Kakuda, a graduate student of our laboratory for his assistance with scanning electron microscopy ; and Professor E. W. Jameson, Jr. University of California for comments on the manuscript. This work was supported in part by a Grant-in-Aid from the Ministry of Education, Science and Culture, Japan (No. 61560310).

\section{REFERENCES}

Arthur, D. R. 1946 The feeding mechanism of Zxodes ricinus L. Parasitology, $37: 154-162$

Arthur, D. R. 1951 The capitulum and feeding mechanism of Zxodes hexagonus Leach. Parasitology, 41: $66-81$

Arthur, D. R. 1957 The capitulum and feeding mechanism of Demacentor parumapertus Neumann 1901. Parasitology, $47: 1699184$

Arthur, D. R. 1962 Tick and Disease. Pergamon Press, Oxford

Arthur, D. R. 1965 Feeding in ectoparasitic acari with special reference to ticks. Adv. Parasit., 3 : 249-298

Balashov, Yu. S. 1972 Bloodsucking ticks (Ixodoidea) - Vectors of diseases of man and animals. Transl. by 0. G. Strekalovsky, Misc. Publ. Ent. Soc. Am., 8: 161-376

Gregson, J. D. 1960 Morphology and functioning of the mouthparts of Demacentor andersoni Stiles. Acta Trop., 17: 48-79

Guirgis, S. S. 1971 The subgenus Persicargas (Ixodoidea, Argasidae, Argas). 13. Histological studies on A. (P.) arboreus Kaiser, Hoogstraal and Kohls. J. Med. Ent., 8: 648-667

Kemp, D. H., B. F. Stone and K. C. Binnington 1982 Tick attachment and feeding: Role of the mouthparts, feeding apparatus, salivary gland secretions and the host response. In "Physiology of Ticks", ed. by F. D. Obenchain and R. Galun, Pergamon Press, Oxford, pp. 119-168

Kemp, D. H. and R. J. Tatchell 1971 The mechanism of feeding and salivation in Boophilus microplus (Canestrini, 1887). Z.Parasitenk., 37 : 55-69

Kitaoka, S. 1967 Some characteristic features of feeding in ticks. Jpn.Agr. Res. Q., 2: 18-21

Kitaoka, S. 1977 Feeding and water-ion balance in ticks. In "Contributions to Acarology in Japan", ed. by M. Sasa and J. Aoki, Hokuryukan, Tokyo, pp. 473-487 (In Japanese)

Nuttall, G. H. F., W. F. Cooper and L. E. Robinson 1908 The structure and biology of Haemaphysalis punctata, Canestrini and Fanzago. Parasitology, $1: 152-181$

Robinson, L. E. and J. Davidson 1913a The anatomy of Argas persicus (Oken 1818). Part I. Parasitology, $6: 20-48$

Robinson, L. E. and J. Davidson 1913b The anatomy of Argas persicus (Oken 1818). Part II. Parasitology, $6: 217-256$

Saito, Y. 1960 Studies on ixodid ticks. Part IV. The internal anatomy in each stage of Haemaphysalis flava Neumann, 1897. Acta Medica et Biologica, 8: 189-239

Sen, S. K. 1935 The mechanism of feeding in ticks. Parasitology, $27: 355-368$ 
Sonenshine, D. E. and J. D. Gregson 1970 A contribution to the internal anatomy and histology of the bat tick Omithodoros kelleyi Cooley and Kohls, 1941. 1. The alimentary system, with notes on the food channel in Ornithodoros denmarki Kohls, Sonenshine, and Clifford, 1965. J. Med. Ent., $7: 46-64$

Till, W. M. 1961 A contribution to the anatomy and histology of the brown ear tick Rhipicephalus appendiculatus Neumann. Mem. Ent. Soc.S.Afr., 6: 1-124

Waladde, S. M. and M. J. Rice 1982 The sensory basis of tick feeding behaviour. In "Physiology of Ticks", ed. by F. D. Obenchain and R. Galun, Pergamon Press, Oxford, pp. 71-118 